\title{
Series editors' foreword
}

\author{
John Solomos, Satnam Virdee, Aaron Winter
}

1 HE STUDY OF race, racism and ethnicity has expanded greatly
from the end of the twentieth century onwards. This expansion has coincided with a growing awareness of the continuing role that these issues play in contemporary societies all over the globe. Racism, Resistance and Social Change is a new series of books that seeks to make a substantial contribution to this growing field of scholarship and research. We are committed to providing a forum for the publication of the highest quality scholarship on race, racism, anti-racism and ethnic relations. As Editors of this series we would like to publish both theoretically driven books and texts with an empirical frame that seeks to further develop our understanding of the origins, development and contemporary forms of racisms, racial inequalities and racial and ethnic relations. We welcome work from a range of theoretical and political perspectives and as the series develops we would ideally want to encourage a conversation that goes beyond specific national or geopolitical environments. While we are aware that there are important differences between national and regional research traditions we hope that scholars from a variety of disciplines and multidisciplinary frames will take to opportunity to include their research work in the series.

As the title of the series highlights we would also welcome texts that can address issues about resistance and anti-racism as well as the role of political and policy interventions in this rapidly changing field. The changing forms of racist mobilisation and expression that have come to the fore 
in recent years have highlighted the need for more reflection and research on the role of political and civil society mobilisations in this field.

We are committed to building on theoretical advances by providing an arena for new and challenging theoretical and empirical studies on the changing morphology of race and racism in contemporary societies. 